$\begin{array}{ll} & \text { Etnográfica } \\ \text { etnográfica } & \text { Revista do Centro em Rede de Investigação em }\end{array}$

Antropologia

vol. $17(2) \mid 2013$

Vol. $17(2)$

\title{
"Era um hino de fábrica apitando": a memória do trabalho negro na cidade de Novo Hamburgo (RS), Brasil
}

"It was a hymn of factory horns whistling": black work memory in the city of Novo Hamburgo (RS), Brazil

Margarete Fagundes Nunes, Ana Luiza Carvalho da Rocha, Magna Lima Magalhães e Norberto Kuhn Junior

\section{(2) OpenEdition}

\section{Journals}

Edição electrónica

URL: https://journals.openedition.org/etnografica/3122

DOI: 10.4000/etnografica.3122

ISSN: 2182-2891

\section{Editora}

Centro em Rede de Investigação em Antropologia

\section{Edição impressa}

Data de publição: 1 junho 2013

Paginação: 269-291

ISSN: 0873-6561

\section{Refêrencia eletrónica}

Margarete Fagundes Nunes, Ana Luiza Carvalho da Rocha, Magna Lima Magalhães e Norberto Kuhn Junior, «"Era um hino de fábrica apitando": a memória do trabalho negro na cidade de Novo Hamburgo (RS), Brasil», Etnográfica [Online], vol. 17 (2) | 2013, posto online no dia 20 junho 2013, consultado o 09 fevereiro 2022. URL: http://journals.openedition.org/etnografica/3122 ; DOI: https:// doi.org/10.4000/etnografica.3122

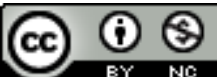

Etnográfica is licensed under a Creative Commons Attribution-NonCommercial 4.0 International License. 


\section{"Era um hino de fábrica apitando": a memória do trabalho negro na cidade de Novo Hamburgo (RS), Brasil}

\section{Margarete Fagundes Nunes, Ana Luiza \\ Carvalho da Rocha, Magna Lima Magalhães \\ e Norberto Kuhn Junior}

O artigo propõe uma reflexão sobre cidade, memória, trabalho e relações etnicorraciais, reunindo elementos de pesquisa etnográfica desenvolvida na cidade de Novo Hamburgo, especialmente com trabalhadores negros que estiveram ligados às indústrias do Vale do Rio dos Sinos a partir de 1960. O artigo apoia-se no estudo das imagens fundacionais da cidade e da região e no estudo de narrativas etnobiográficas de trabalhadores negros, a fim de compreender como as trajetórias e itinerários urbanos desses sujeitos relacionam-se com o valor trabalho e com as representações e imagens da industrialização da cidade e da região.

PALAVRAS-CHAVE: cidade, memória, trajetória, trabalho, negros, relações etnicorraciais.

"It was a hymn of factory horns whistling": black work memory in the city of Novo Hamburgo (RS), Brazil - The present article presents an analysis of aspects such as city, memory, work, and ethno-racial relations, including elements of an ethnographic research developed in the city of Novo Hamburgo. This study involved mainly black workers who have worked at the factories of Vale do Rio dos Sinos since 1960. The paper is based on the study of foundational images of the city and region and on the study of ethnobiographical narratives from the black workers in order to understand how their trajectories and urban itineraries relate to the work value and to the representations and images of industrialization of the city and region.

KEYWORDS: city, memory, trajectory, work, blacks, ethnic-racial relations.

NUNES, Margarete F. (marga.nunes@feevale.br) - Universidade Feevale, Brasil. ROCHA, Ana L. Carvalho da (analuiza2@feevale.br) - Universidade Feevale, Brasil. MAGALHÃES, Magna Lima (magna@feevale.br) - Universidade Feevale, Brasil. KUHN JUNIOR, Norberto (nkjunior@feevale.br) - Universidade Feevale, Brasil. 
PARA A DISCUSSÃO DESTE ARTIGO, APRESENTAMOS PARTE DOS registros textuais de narrativas etnobiográficas e dos registros visuais de acervos documentais da pesquisa realizada com trabalhadores negros na cidade de Novo Hamburgo, no Rio Grande do Sul. ${ }^{1}$ As falas dos interlocutores da pesquisa, os "narradores do trabalho", dão visibilidade às suas experiências urbanas marcadas por diferenças etnicorraciais, ${ }^{2}$ ao mesmo tempo em que revelam as desigualdades sociais e raciais presentes na edificação do trabalho no Vale do Rio dos Sinos. ${ }^{3}$ A pesquisa teve início no ano de 2010, com prazo de execução até 2012. Neste período, foram registradas cerca de 20 narrativas biográficas, nas suas formas textuais, visuais e sonoras, com trabalhadores, homens e mulheres, habitantes de Novo Hamburgo e região. A escolha dos "narradores do trabalho" deu-se a partir de uma rede de contatos estabelecida junto às comunidades negras e entidades representativas do movimento negro em Novo Hamburgo. ${ }^{4}$

No plano da memória social do Vale do Rio dos Sinos, partimos do reconhecimento de que o valor trabalho é marca identitária da região e, portanto, força aglutinadora da memória coletiva das comunidades urbanas locais (Nunes 2009). Em um primeiro momento, apontamos dados da história social de Novo Hamburgo e do processo de colonização alemã na conformação da cultura urbana da região, valorizando a discussão acerca das imagens e representações do "mundo dos brancos" (Fernandes 2007) sob as quais se alicerça a memória social do mundo do trabalho. Num segundo momento, enfocamos as transformações do mundo do trabalho fabril e industrial no Vale do Rio dos Sinos e a quebra do imaginário urbano da colonização alemã em Novo

I Este artigo é resultado de uma pesquisa desenvolvida na Universidade Feevale, intitulada "As comunidades negras do Vale do Rio dos Sinos e a memória do trabalho", que teve o apoio da FAPERGS - Fundação de Amparo à Pesquisa do Estado do Rio Grande do Sul - no ano de 2010. A pesquisa contou com o apoio do Banco de Imagens e Efeitos Visuais da Universidade Federal do Rio Grande do Sul, por meio da sua associação ao projeto "Trabalho e cidade: antropologia da memória do trabalho na cidade moderno-contemporânea", coordenado pela doutora Cornelia Eckert.

2 Optamos pela utilização dos dois conceitos de etnia e raça considerando-se o seu imbricamento no movimento social contemporâneo. Enquanto o conceito de raça reforça as identificações baseadas na cor e na fenotipia, os conceitos de etnia/etnicidade referendam as mobilizações políticas centradas na ideia de uma "pertença étnica" (Nunes 2009).

3 Novo Hamburgo, ao lado de mais treze municípios, integra o chamado Vale do Rio dos Sinos. A população total do Vale é de 1.298 .362 habitantes; possui uma área de 1398,5km²; densidade demográfica de 928,4 habitantes $/ \mathrm{km}^{2}$; taxa de analfabetismo de 3,10\%; expectativa de vida ao nascer de 71,76 anos; coeficiente de mortalidade infantil de 10,79 por mil nascidos vivos; PIB per capita de BRL R\$ 29.219; exportações totais (FOB) de USD \$2.343.973.998, segundo dados apresentados no website da FEE, $<$ http://www.fee.tche.br/sitefee/pt/content/resumo/pg_coredes_detalhe.php?corede $=$ Vale + do + Rio + dos + Sinos $>$ (acessado em 30/4/2013).

4 Utilizamos a denominação comunidades negras por essa assumir característica de categoria êmica, fazendo parte da linguagem habitual dos interlocutores da pesquisa. A identidade desses interlocutores foi preservada, adotando-se nomes fictícios. 
Hamburgo, desencadeadas por um processo de desindustrialização da região, de deslocamento do capital local e da mão de obra para outras regiões do país e mesmo para o estrangeiro, em particular para o Nordeste do Brasil e para a China (Pereira 2002).

Finalmente, abordamos a invisibilidade da presença de populações de afrodescendentes no interior das imagens fundacionais de Novo Hamburgo, sua presença em alguns dos bairros proletários, assim como as suas formas de inserção na paisagem citadina local. ${ }^{5}$ Operamos com o conceito de invisibilidade a partir de Oliven (1996), que, ao analisar a construção da identidade regional gaúcha, chama a atenção para a invisibilidade social e simbólica do negro no Rio Grande do Sul (RS), sobretudo, assinalando tanto a exclusão quanto a valoração negativa da imagem do negro nas narrativas literárias, sociológicas, historiográficas e folclóricas. Diferentemente de outras regióes brasileiras, onde a figura do negro foi realçada positivamente - por exemplo, na região Nordeste o autor enfatiza que no Rio Grande do Sul ocorreu um movimento inverso. A leitura acerca da invisibilidade social e simbólica do negro no RS proposta por Oliven (1996) é útil, neste artigo, para a compreensão dos mecanismos de esquecimento e lembrança presentes nos jogos da memória, especialmente no que se refere à memória do trabalho em Novo Hamburgo e região. No entanto, ressaltamos que o processo de exclusão e invisibilidade das populações negras tem sido historicamente confrontado e colocado em xeque, seja pelo modo de vida dessas populações, através de suas associações e manifestações culturais, de suas formas de sociabilidade e de afirmação étnica, seja pela luta política protagonizada pelo movimento negro, ou, ainda, pela disputa que ocorre no plano das ideias e dos conceitos, presente no espaço acadêmico e nos movimentos sociais.

Em cada um dos momentos apresentados, procuramos enfocar as transformações dos ritmos do mundo do trabalho fabril e industrial (da abundância à crise), em Novo Hamburgo, como rupturas e descontinuidades espaçotemporais da vida urbana local, nos moldes dos estudos de uma "etnografia da duração" (Eckert e Rocha 2005). Para tal perspectiva, a dos estudos do imaginário (Durand 2002), os fenômenos da memória revelam a presença de uma "métrica singular" produzida pela inteligência humana e capaz de fazer operar uma seriação para os acontecimentos vividos, segundo uma ordem de sucessão de intervalos de espaço-tempo.

5 Para a compreensão das imagens fundacionais da cidade de Novo Hamburgo, faz-se menção ao conceito de imaginário tal qual elaborado por Gilbert Durand, segundo o qual o imaginário não é a mera representação da vida social e material; a matéria do imaginário pressupõe uma troca, uma gênese recíproca entre as pulsões subjetivas do indivíduo e as intimações objetivas. Assim, “o imaginário não é mais que esse trajeto no qual a representação do objeto se deixa assimilar e modelar pelos imperativos pulsionais do sujeito" (Durand 2002: 41). 
Nestes termos, a etnografia da duração do mundo do trabalho, em adesão aos estudos bachelardianos da "dialética da duração" (Eckert e Rocha 2009: 106-107), distancia-se dos estudos bergsonianos da memória, ao preocupar-se com as formas como os narradores e contadores de histórias, imersos no plano da imaginação criadora, constroem e reconstroem inteligentemente a matéria de suas vidas vividas na esfera da produção. Estas narrativas se desdobram de forma ininterrupta e não linear, por equilibrações sucessivas e reversíveis dos intervalos e dos instantes vividos; são relatos de tempos vividos, contendo descontinuidades e rupturas, nos quais ora preponderam os instantes do tempo da abundância, ora o tempo da crise e do fechamento das fábricas. $\mathrm{Na}$ busca de cadência para os instantes vividos, nascem temporalidades narradas e performatizadas através de reestruturações de operações de pensamento e construções sucessivas, em níveis diferentes de aproximação com o conteúdo das experiências na cidade de Novo Hamburgo.

Interessa-nos compreender, portanto, nas falas de trabalhadores afrodescendentes, a dimensão temporal de suas experiências do trabalho fabril e industrial na cidade, onde os jogos da memória de nossos interlocutores não os reduzem ao papel de "contadores de histórias" do passado da paisagem urbana local. Ao contrário, em adesão à etnografia da duração, os relatos de nossos parceiros de pesquisa revelam que suas memórias do mundo do trabalho não são indiferentes aos processos de suas vidas vividas no interior das fábricas e indústrias locais, tampouco aos mecanismos de esquecimento e lembrança acionados para a construção do período de abundância e riqueza da região do Vale do Rio dos Sinos. O ato de lembrar o cotidiano operário entre nossos interlocutores manifesta claramente operações de pensamento complexas, autorreguladoras e autocorretivas dos processos de transformação aos quais a matéria do vivido acha-se submetida, conduzida reflexivamente e sujeita ao devir dos seus pensamentos. Assim, as classificações de raça/etnia revelam-se interessantes para se compreender os laços que unem as memórias do trabalho da imigração alemã àquelas da mão de obra de populações negras em Novo Hamburgo.

No sentido de captar a dimensão do arranjo espaçotemporal que acompanha os relatos de nossos parceiros de pesquisa sobre o mundo do trabalho em Novo Hamburgo é que nos filiamos aos estudos de etnobiografias (Preloran 1987), de trajetórias sociais (Velho 1999) e de itinerários urbanos (Eckert e Rocha 2005), buscando compreender como se apresentam as variações dos jogos da memória na esfera da produção fabril e industrial da região, sem perder de vista as diferenciações de classe, raça e etnia. Trata-se de olhar de forma mais atenta para o arranjo estético das lembranças de nossos narradores urbanos sobre o mundo do trabalho como forma de interpretar o lugar que, no instante presente, esses ocupam na paisagem urbana de Novo Hamburgo.

Tempo passado e tempo presente não se opõem, ao contrário, ambos aparecem superpostos, revelando uma tensão entre rupturas e continuidades. 
Parodiando as palavras das autoras em que este artigo se apoia (Eckert e Rocha 2005: 153), as memórias do trabalho na região gravitam entre o desejo de reconhecimento do valor da mão de obra das populações negras no interior da paisagem urbana, cada vez mais ameaçada pela situação de desindustrialização, e o culto à imigração alemã como responsável pelos tempos de abundância e de progresso em Novo Hamburgo.

Em especial, explorar a cidade de Novo Hamburgo a partir dos jogos da memória de seus habitantes significa explorar a diversidade temporal do conhecimento humano adaptado à vida, cada qual seguindo um ritmo apropriado, de acordo com um ponto de vista particular, o dos nossos encontros como etnógrafos com nossos parceiros de pesquisa. Assim, à medida que esses sujeitos narram suas experiências urbanas com o mundo da produção fabril e industrial do Vale do Rio dos Sinos, os espaços de sociabilidade, as brincadeiras de infância pelas ruas da cidade, os conflitos etnicorraciais, a vida em família, as festas, as dificuldades de promoção no trabalho, as possibilidades de ascensão social, misturam a sua trajetória e biografia etnicorracial ao território da cidade.

Sob este ângulo, os relatos obtidos sobre o mundo do trabalho na região do Vale do Rio dos Sinos não se diferenciam daqueles presentes nos estudos sobre a esfera do trabalho em outras cidades brasileiras. Nas histórias narradas reverberam muitos acontecimentos de discriminação e exclusão social, os quais também estão presentes em outras pesquisas que abordam os saberes e fazeres dos grupos etnicorraciais formadores da sociedade brasileira, em especial das populações negras no contexto dos grandes centros urbano-industriais do país (Andrews 1998; Fernandes 2007, 2008).

\section{DO MITO HISTÓRICO AO MITO DO PROGRESSO}

A cidade de Novo Hamburgo localiza-se no estado do Rio Grande do Sul, encontra-se a cerca de 40 quilômetros de sua capital, Porto Alegre, e nasce às margens da rodovia BR 116 , a principal rodovia do Brasil totalmente pavimentada, que atravessa longitudinalmente o país, tendo seu início na cidade de Fortaleza, no estado do Ceará, e o seu término na cidade de Jaguarão, no Rio Grande do Sul, na fronteira com o Uruguai.

Novo Hamburgo nasceu dentro de uma faixa de terra que, até o ano de 1927, pertencia à cidade de São Leopoldo - considerada cidade-mãe dos imigrantes alemães no Brasil, e originária no tempo mítico da chegada das primeiras famílias alemãs no Vale do Rio dos Sinos, no início do século XIX. No corpo da narrativa do mito histórico considera-se, assim, o ano de 1824 o marco simbólico da chegada das primeiras famílias alemãs na região para a edificação de uma memória oficial das origens do trabalho fabril e, logo após, industrial. No mito de fundação de São Leopoldo, consta que o presidente da província, 
José Feliciano Fernandes Pinheiro, ${ }^{6}$ teria pedido autorização para a troca do antigo nome Feitoria do Linho Cânhamo para São Leopoldo, em homenagem à Dona Leopoldina, esposa de $\mathrm{D}$. Pedro I. Na época, a região onde hoje se situa Novo Hamburgo abrigava um vilarejo e era denominada Nossa Senhora da Piedade ou Hamburger Berg. ${ }^{7}$

Até o período da colonização alemã, a região do Vale do Rio dos Sinos, situada no nordeste do Rio Grande do Sul, era ocupada por portugueses, açorianos e seus descendentes, africanos e descendentes de africanos, num convívio difícil com as populações indígenas locais, predominantemente com os kaingangs, que eram chamados de "coroados" ou "bugres".

Ao longo do período colonial, a região abrigava "moradores de terras devolutas que ali tinham suas lavouras" e "não exihibiam os seus títulos" (Porto 1934: 18) e "sesmeiros" - portadores do título de sesmaria -, alguns vindos de Laguna e São Paulo, outros que teriam migrado da Colônia de Sacramento em virtude dos intermitentes conflitos com os castelhanos (Moraes 1994). Este foi descrito como um lugar "que parecia fadado a um grande núcleo agrícola, e onde, mais tarde, se inicia o trabalho livre, do braço alemão que engrandeceu o Rio Grande do Sul..." (Porto 1934: 18).

A Real Feitoria do Linho Cânhamo, que depois de 1822 passou a se chamar Imperial Feitoria do Linho Cânhamo, instalou-se na região somente em 1788, na localidade então designada Faxinal do Courita, ${ }^{8}$ vindo transferida da região de Canguçu. ${ }^{9}$ As terras do Faxinal, ao sul do Rio dos Sinos, não eram suficientes para abrigar as necessidades da feitoria, o que obrigou ao uso das terras ao norte do Rio dos Sinos, já ocupadas por várias famílias (Moraes 1980). A feitoria foi criada com o propósito de produzir o linho e transformá-lo para a fabricação de cordas para as embarcações. A mão de obra era constituída por negros e indígenas. Segundo o relato de alguns historiadores, a tentativa foi fracassada tanto em Canguçu quanto no Faxinal. Em ambas as feitorias, a presença da mão de obra escrava ${ }^{10}$ na produção do cânhamo aludia aos maus-tratos infligidos a esta população pelos administradores locais e às péssimas condições de vida dos negros na região: vivendo em "senzalas cobertas de capim", submetidos a "castigos corporais inauditos" na forma de "açoites que

6 Mais tarde conhecido como Visconde de São Leopoldo.

7 Petry (1944) faz menção ao nome de Nossa Senhora da Piedade de Hamburger Berg. Entre as famílias alemãs era comum a designação Hamburger Berg.

8 Alusão ao apelido de Antônio Araújo Vilela, português procedente da região de Coura, distrito de Braga, na época (Moraes 1994: 24).

9 Canguçu situa-se no extremo sul, na microrregião de Pelotas e da mesorregião Sudeste, conforme as divisões utilizadas pela FEE/RS - Fundação de Economia e Estatística do Rio Grande do Sul.

10 No decorrer do artigo, usamos a expressão mão de obra escrava em referência ao período anterior à abolição da escravatura; a expressão mão de obra negra é usada para sinalizar o trabalho feito pelos negros após essa abolição, já no contexto do trabalho livre. 
lanhavam a carne", presos que estavam a um "tronco infamíssimo" (Porto 1934: 25-27).

O fracasso da produção de linho vem associado não só à mão de obra escrava, mas à imagem da terra estéril para a região dos "campos de São Leopoldo" - "terreno impróprio e incômodo para esta indispensável cultura", "formado de lombas, altas e secas, composto de uma argila vermelha e estéril, como bem dá a conhecer a sua nudez", nas palavras do padre Antônio Gonçalves da Cruz, capelão da feitoria (Cruz apud Porto 1934: 24). Esta imagem forte de uma terra imprópria, de "terra caluniada", entretanto, vai contrastar com a imagem da abundância quando submetida à presença do braço do colono alemão, que inaugura o trabalho livre, "tornando-a o grande celeiro da produção agrícola da Província” (Porto 1934: 25). O abandono da plantação de cânhamo dá origem aos benefícios de uma grande fazenda de criação de gados para a exploração principalmente do couro que, mais tarde, "até os dias de hoje, a indústria alemã transformaria na maior fonte de riqueza particular e pública, que opulenta a região colonial do Estado" (Porto 1934: 27).

Alguns autores, ao ressaltarem o fracasso da feitoria, tendo em vista a inadaptação da terra ao cultivo do cânhamo e a falência do processo de produção do linho a partir do trabalho escravo, justificam a destinação das terras para o propósito da imigração alemã (Moraes 1994; Cesar 1970). Por outro lado, as terras entregues aos colonos recém-chegados à Província eram "terras não aproveitáveis para a pecuária" - marca da identidade da sociedade gaúcha. Os imigrantes, assim, eram alocados em "regiões florestais onde tiveram de se confrontar com os párias da

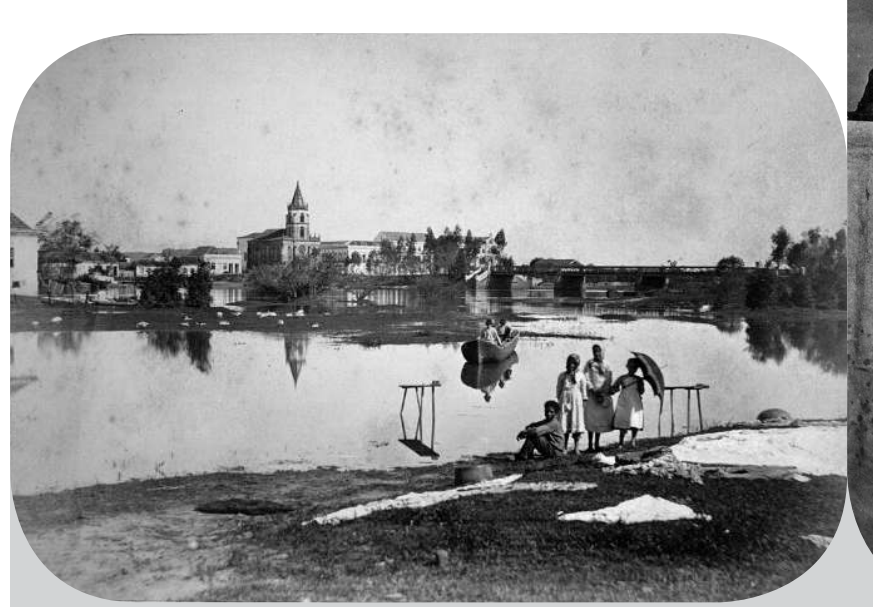

Figura 1 - Rio dos Sinos, São Leopoldo, século XIX (fotografia de A. Stoeckel).

Fonte (figs. 1 e 2): Acervo Benno Mentz, PUCRS.

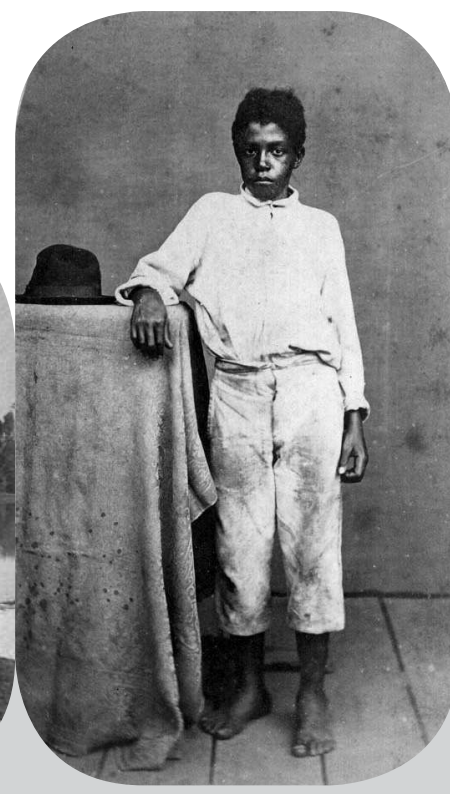

Figura 2 - Trabalhador das plantações, RS (fotografia de A. Stoeckel). 
sociedade, já estabelecidos e longamente mestiçados com os índios, e com os próprios indígenas" (Porto 1934: 310).

A oposição entre trabalho escravo e trabalho livre alimenta a memória da imigração alemã associada não apenas ao mito histórico, mas à sua reelaboração nos moldes do mito do progresso (Durand 2002), em referência aos gestos tradicionais de apropriação da terra no Rio Grande do Sul - a pecuária e a agricultura extensiva - realizados por outros grupos etnicorraciais, que despontam como agentes de experiências fracassadas na região. ${ }^{11}$

A presença dos colonos alemães no Vale do Rio dos Sinos não significou a retirada imediata da antiga população de suas terras. ${ }^{12}$ Houve dificuldade na implantação das colônias, tanto pela reação indígena quanto pela reclamação dos "sesmeiros" - especialmente aqueles que não cumpriam com os preceitos da carta de concessão que os obrigava a demarcar e cultivar suas terras sob o risco de estas serem desapropriadas.

Nas narrativas dos cronistas e viajantes europeus que visitaram a região, são inúmeras as versões encontradas sobre o processo de instalação de uma civilização urbana no Vale do Rio dos Sinos, e elas tecem os vínculos entre o mito do progresso e suas imagens correlatas, da abundância e da riqueza, a partir da chegada dos colonos no Rio Grande do Sul, um acontecimento que integra o mito histórico da emigração de cinco milhões de alemães, das mais diversas regiões, para o Novo Mundo, no século XIX. É, portanto, frequente a referência à saga do recrutamento dos imigrantes na Europa, às condições difíceis da viagem para o Novo Mundo e, posteriormente, ao abandono pelo governo da província que, no Brasil, teria entregado os colonos à sua própria sorte, onde "muitos malogravam encobrir sua nudez, e cujas atitudes traziam o cunho da rudeza e da bestialidade animais" (Edmund Teodoro Boesch apud Porto 1934: 44).

Ainda que submetidas aos parâmetros básicos para a ocupação do solo impostos pelo governo provincial, as terras destinadas aos colonos foram alvo de intensas disputas territoriais (Weimer 1987), tendo os alemães que compartilhar, por exemplo, o território com os negros e conviver com a presença da mão de obra escrava na região.

Algumas obras literárias fazem menção ao abandono do colono, que fica “à mercê da sorte nas florestas inóspitas povoadas de indígenas" e se submete ao convívio forçado com as populações escravas. É o caso de A Ferro e Fogo I - Tempo de Solidão, de Josué Guimarães (1996: 13), que apresenta o casal Daniel Abrahão Schneider e Catarina Schneider, protagonistas da obra, vivendo na região da feitoria: “... a Feitoria era pocilga para negro, e até então só negro

I I Segundo Durand (2002), o mito do progresso conforma uma modalidade simbólica do tempo distinta daquela que o mito histórico instaura, traduzindo-se pelo aperfeiçoamento deste último.

12 Para as dificuldades de implantação das colônias na extinta Feitoria do Linho Cânhamo, ver Moraes (1980, 1994). 
vivera ali, muito justo, o que não tinha explicação era ele, um Schneider, mais a mulher e o filho, confinados naquele estábulo, bem que mereciam um destino melhor".

Nos primeiros anos, os relatórios de inspetoria descrevem os colonos alemães, esta "gente infeliz", como "cheia de miséria", vivendo os primeiros tempos sem os subsídios prometidos pelo governo imperial, sofrendo em condições "dignas de comiseração". Entretanto, na vibração do tempo de mais de um século, redescobrimos os colonos alemães do Vale do Rio dos Sinos reverenciados em inúmeros escritos - sejam esses literários, jornalísticos, históricos ou sociológicos - como um povo "digno de louvor", numa clara associação entre a etnicidade alemã e o mito do progresso para a região do Vale do Rio dos Sinos, em prol da "boa ordem, do sossego e da tranquilidade" (Porto 1934: 1 14).

É importante destacar a preocupação dos poderes públicos, em meados do século XIX, com a entrada de escravos nas colônias, criando-se para isto leis especiais para a região do Vale do Rio dos Sinos, o que indica a prática usual de mão de obra escrava nos trabalhos que se realizavam nas colônias existentes (Porto 1934).

$\mathrm{Na}$ linha de estudos acerca da presença da mão de obra escrava na configuração da civilização urbana e industrial no Vale do Rio dos Sinos, destacamos o trabalho de Alves (2005), o qual informa que, entre os anos de 1850 e 1870, a edificação das cidades na região contou com a força do trabalho escravo. Os rastros da presença negra na edificação da civilização urbana em Novo Hamburgo e a reverberação de suas imagens serão retomados posteriormente na fala de alguns dos nossos parceiros de pesquisa, no momento em que narram as suas experiências familiares no mercado de trabalho da cidade.

Opondo-se à imagem da "desorganização administrativa da província" e perseverando a imagem da etnia alemã como aquela que foi capaz de transformar a paisagem do Vale do Rio dos Sinos, antes uma "senzala de escravos", numa "colônia de livres", consolida-se, assim, para Novo Hamburgo, em particular, a visão da "Manchester brasileira". A partir de sua autonomia política, em 1927, Novo Hamburgo se afirma gradativamente como polo industrial e urbano na região, território de opulência e abundância, onde os apitos das fábricas soavam como um hino. Esta imagem forte faz com que a cidade seja reconhecida, ainda hoje, em meio a um violento processo de desindustrialização, como a capital brasileira do calçado, cuja produção até meados do século XX abastecia o mercado interno brasileiro, um panorama que se amplifica quando, na década de 1970, volta-se ao mercado internacional, ocupando nele um papel expressivo até a virada do século.

Novo Hamburgo, como expressão do esforço fecundo do alemão na construção da grandeza econômica do Rio Grande do Sul, fez do mundo do trabalho livre, em sua feição industrial e comercial, símbolos representativos de um tipo étnico singular no interior da gente rio-grandense. A figura do alemão, portanto 
do trabalho livre, e do seu amor pelo Rio Grande e pelo Brasil serviu como alicerce às representações simbólicas de Novo Hamburgo como uma cidade ordeira, trabalhadora, que acorda cedo e que se dedica intensamente à ética do trabalho.

Ao longo deste período em que vigoraram as imagens da abundância e da riqueza, deve-se mencionar o fato de que a cidade de Novo Hamburgo despertou o interesse de trabalhadores de outros municípios, que migraram para a cidade com o objetivo de trabalhar nas fábricas de calçados e de componentes para calçados e nos curtumes. Assim, a "Manchester brasileira" revivia outra imagem, mais arcaica, associada ao nascimento da civilização sob os trópicos: era nominada de "Eldorado gaúcho", em alusão às oportunidades de trabalho e de emprego e aos sonhos de uma vida melhor.

Entretanto, nos anos 90 do século XX, a região do Vale do Rio dos Sinos passou a experimentar um movimento de refluxo migratório, decorrente da crise da produção coureiro-calçadista que, em décadas anteriores, havia sido o principal foco de atração de populações vindas especialmente da região Noroeste do estado do Rio Grande do Sul (Nunes 2009). Houve deslocamentos de algumas empresas para outras regiões do país, especialmente para os estados do Nordeste, atraídas pelo lucro advindo de incentivos fiscais e da redução de custos de mão de obra (Pereira 2002). Esse movimento atingiu também as fábricas de componentes para calçados, toda uma cadeia produtiva que se desmontou ou se deslocou por causa da baixa produção de calçados, seguindo a rítmica de um processo global de desterritorialização e desenraizamento da força de trabalho. Pelos mesmos motivos, alguns empresários locais foram atraídos pelo mercado chinês para atuar no plano de uma economia globalizada. Nos anos de 2000, deu-se início a um fluxo de emigração para a China, especialmente de trabalhadores especializados em técnicas de produção e comercialização de calçados e componentes para calçados (Kuhn Júnior e Nunes 2012).

É, assim, diante deste quadro situado - de crise do mundo do trabalho e do mito do progresso instaurado pela imigração alemã em Novo Hamburgo que iniciamos a pesquisa com os herdeiros urbanos dos antigos trabalhadores negros na região do Vale do Rio dos Sinos, numa escuta atenta das formas de acomodação deste processo vivido de desindustrialização da "Manchester brasileira", tão em voga no século XX, e da erosão da figura heroica do colono alemão e da ética do trabalho livre do século XIX, que se colocava em confronto direto com a "ideologia do estamento pecuarista que dominava o poder provincial" (Weimer 1987: 104).

O NEGRO E AS EXPERIÊNCIAS DO TRABALHO LIVRE: AS DESIGUALDADES ETNICORRACIAIS NO TEMPO DAS FÁBRICAS

Apesar de se constatar certa escassez de pesquisas e registros oficiais sobre a mão de obra negra nos primórdios da industrialização do calçado no Vale do 
Rio dos Sinos, fragmentos das narrativas biográficas de nossos interlocutores de pesquisa informam a relação direta entre o trabalho com o couro e a ocupação ancestral dos negros em territórios nos quais hoje existem inúmeras cidades da região.

Em referência à própria memória do mundo do trabalho para a formação da sociedade rio-grandense, não se pode esquecer que a indústria do charque (carne seca) no Rio Grande do Sul, iniciada no final do século XVIII, tinha como sustentáculo a mão de obra escrava (Cardoso 1977). Por decorrência, todas as atividades que envolviam a lida com o animal, desde o pastoreio, o abatimento, a salga da carne, bem como o aproveitamento do couro para a fabricação de utensílios, objetos vários, artigos de vestuário e calçado dependiam da mão de obra escrava.

O fato de os negros serem detentores do conhecimento de técnicas de trabalho com o couro apresenta-se como uma possibilidade de explicação para a recorrência, nas narrativas biográficas, da vinculação entre o curtimento do couro e a mão de obra negra nos curtumes do Vale do Rio dos Sinos, com grande concentração, especialmente na primeira metade do século XX. Essa possibilidade de deslocamento de mão de obra escrava e, logo após, na condição de trabalhadores livres afirma-se como relevante para os estudos da etnografia das memórias coletivas das populações negras no Vale do Rio dos Sinos.

Magalhães (2010), ao trabalhar o associativismo negro em Novo Hamburgo, lança mão das certidões de nascimento como fonte histórica, priorizando os anos de 1920 a 1958, e identifica o curtimento do couro como a principal atividade de ocupação dos pais das crianças negras nascidas na cidade - apontada em 122 registros de nascimento, dentre os 268 documentos analisados. Seu Valdir, 87 anos, homem negro, operário e interlocutor da autora, enfatiza em sua fala que "noventa por cento dos que trabalhavam nos curtumes eram negros", tratando-se de pessoas que "não tinham para aonde ir". ${ }^{13}$

A itinerância da mão de obra de ex-escravos apontada por este ancião nos provoca a pensar acerca das escassas oportunidades de trabalho para os negros no Rio Grande do Sul e sua busca de oportunidades no Vale do Rio dos Sinos. Assim, pode-se imaginar que os curtumes, responsáveis pelo mau cheiro que se espalhava por muitas áreas de Novo Hamburgo, contavam especialmente com os trabalhadores negros para as atividades de processamento do couro. Muitos desses trabalhadores eram procedentes do município de Pelotas, que no século XIX abrigou grande parte das charqueadas do Rio Grande do Sul.

A experiência dos negros passou, portanto, num primeiro momento, por uma presença forte nos curtumes da região dos Sinos e uma presença tímida

13 Seu Valdir foi trabalhador nas indústrias da região. Membro da Sociedade Cruzeiro do Sul - um dos mais tradicionais clubes de negros da região, fundado em 1922 - foi diretor de futebol, diretor de Carnaval e três vezes presidente dessa mesma sociedade. 
nas fábricas de calçado. Enquanto as portas das fábricas de calçado estreitavam-se para o trabalhador negro, as portas dos curtumes abriam-se como possibilidade de emprego e sustentação financeira a esse mesmo trabalhador.

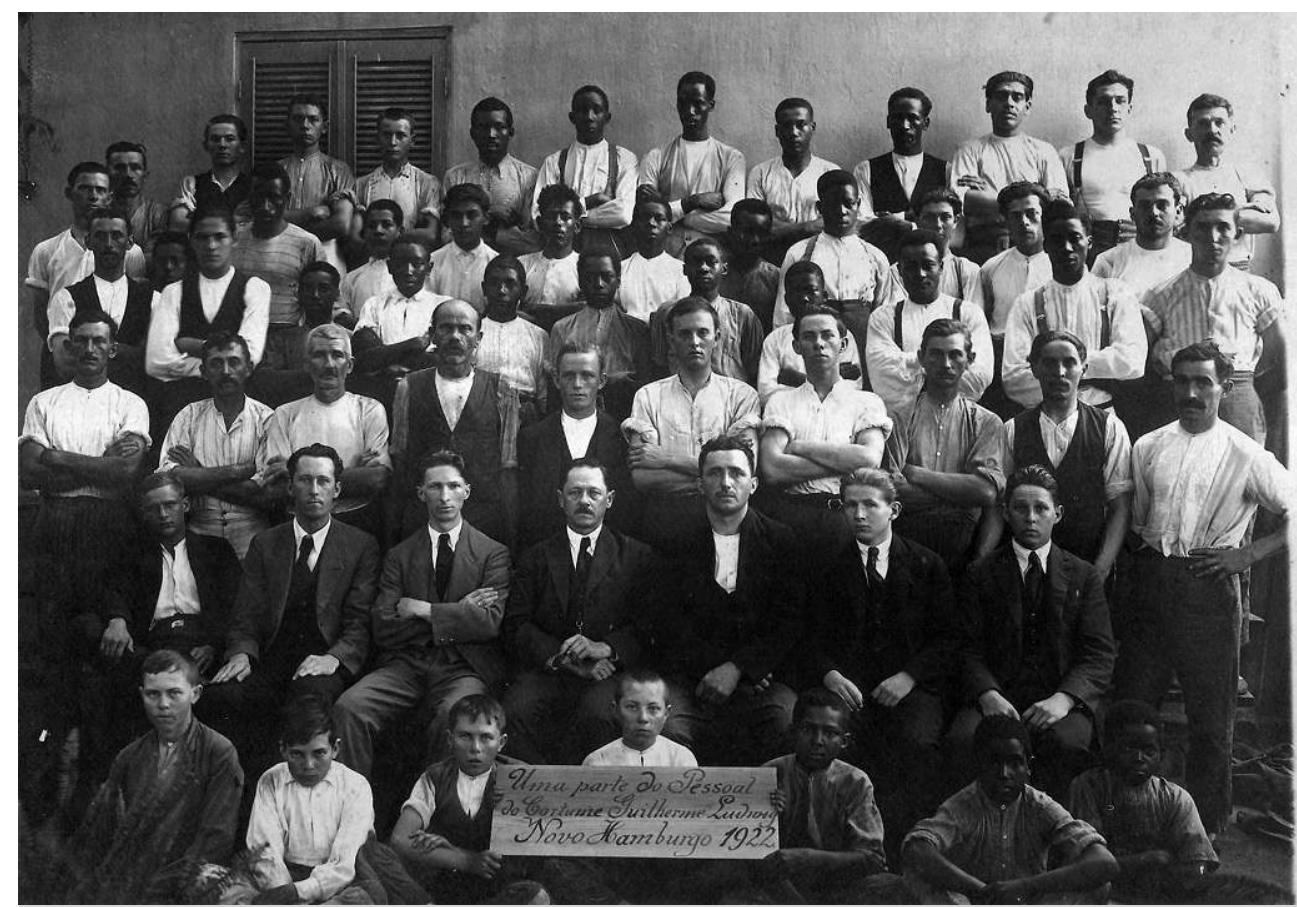

Figura 3 - Trabalhadores do Curtume Ludwig, Novo Hamburgo, 1922.

Fonte: Acervo pessoal de Ângelo Reinheimer, Fundação Ernesto Frederico Scheffel de Novo Hamburgo.

Neste sentido, estabelecia-se no cotidiano da "Manschester brasileira" uma desigualdade material e simbólica entre os trabalhadores da indústria coureiro-calçadista de origem alemã e os de origem africana (ex-escravos), que se caracterizava pela distinção social e moral do "nós" (os teuto-brasileiros) em relação aos "outros" (os negros).

Na obra Trabalho, Poder e Sujeição, Tittoni (2007) mostra o quanto algumas ocupações e saberes práticos, cujos detentores eram as populações de negros, ex-escravos, foram desvalorizados ao longo da história do mundo do trabalho no Brasil. Conforme pondera a autora, a herança de um passado escravocrata atuando no processo de propagação das teorias raciais na formação do Estado nacional brasileiro, em sua fase republicana, no final do século XIX, fez com que o país optasse pelos trabalhadores imigrantes no início da industrialização, integrando tardiamente os trabalhadores "nacionais" ao processo produtivo.

Esse fenômeno se torna evidente no caso dos registros oficiais das memórias do mundo do trabalho alemão no Vale do Rio dos Sinos e é retomado 
nas narrativas etnobiográficas de um de nossos "narradores do trabalho" em Novo Hamburgo, aqui apelidado de Valmor, 61 anos, membro da Sociedade Cruzeiro do Sul, da qual foi diretor de Carnaval por muitos anos, e que, na ocasião da pesquisa, ocupava o cargo de presidente da Associação Brasileira de Estilistas de Calçados e Afins:

“É... Eu, na realidade, sou nativo de Novo Hamburgo, eu sou daqui da terra mesmo, nasci aqui, meus pais são... Minha mãe, de Lomba Grande, meu pai, de Morro dos Bois [zonas rurais de Novo Hamburgo], da colônia lá do Morro dos Bois, se criou na colônia, trabalhou plantando aipim até que numa determinada época ele veio para Lomba Grande, e lá ele encontrou minha mãe, eles casaram, tiveram o primeiro filho em Lomba Grande. Depois de Lomba Grande veio buscar trabalho em Novo Hamburgo. Ela veio buscar trabalho de empregada doméstica e ele conseguiu trabalho... Já com filho, né! E ele conseguiu trabalho numa envernizaria de couro. Acho que foi ali que eu comecei a sentir a influência do couro, já antes mesmo de ter nascido."

Segundo nosso interlocutor de pesquisa, o domínio das técnicas de lida com o couro foi transmitido pelo pai, oriundo da colônia de Morro dos Bois, o que o faz "sentir a influência do couro já antes de ter nascido", significando, portanto, uma experiência transgeracional:

"E o falecido papai, ele trabalhou numa envernizaria de couro onde naquela época o couro era, era envernizado manual... Era um líquido, uma pasta tipo um piche, tipo esse... Essa massa asfáltica. E aquilo era passado com uma espátula em cima de um couro, né! Com uma lixa... Anteriormente ele era lixado, bem liso, né!, para depois eles aplicarem aquilo com uma massa quente, com uma espátula. Era um trabalho sofrido. Eu lembro que o papai suava muito uma época, porque era quente aquela massa, e ele, ali, trabalhava. Até que em uma determinada época ele se adoentou, não pôde mais trabalhar, se aposentou e... Mas eu acho que ali começou meu gosto pelo couro, né!, já antes mesmo de eu ter nascido."

A miserabilidade dos trabalhadores das indústrias e especialmente dos curtumes, bem como as dificuldades enfrentadas em um cotidiano de exclusão, empurravam esses sujeitos para a área periférica, onde se encontrava um número significativo de curtidores e sapateiros que engrossavam as filas dos trabalhadores das indústrias.

Colocados à margem da cidade próspera e ordeira, eram excluídos não só da vida cotidiana da cidade, mas também das representações e imagens de trabalhadores responsáveis pelo avanço da cidade. 
Em trabalho anterior de uma das autoras deste artigo (Nunes 2009) foi mostrada a especificidade das relações raciais no Vale do Rio dos Sinos. Ao estabelecermos um diálogo estreito com a obra de Florestan Fernandes (2007) O Negro no Mundo dos Brancos, afirmámos que nesta região a ideologia do branqueamento recebeu novos ingredientes, pois, ali, o negro não estava tão-somente diante da divisão entre o "mundo dos brancos" e o "mundo dos negros", mas confrontava-se com a instauração de um "mundo alemão", que operava no plano do simbólico. Esta dimensão é relevante nas memórias do tempo vivido nos curtumes, reverbera no tempo pensado, nas lembranças de infância de Seu Valmor sobre o seu pai:

"Então, essa história do papai me lembra muito, que ele brigava muito com o patrão, ele achava que o patrão era muito injusto com ele, e o patrão era daqueles Reichert de origem alemã, né! Uma pessoa muito dura, muito seca. E ele chegava em casa triste com o patrão e brigava com o patrão, mas não brigava lá com o patrão, brigava em casa, né! Xingava o patrão em casa. Mas ele... Uma pessoa muito responsável, muito honesta, muito direita, apesar de ter uma situação de vida bastante... É... É... Pobre, ele tinha que trabalhar muito, minha mãe trabalhava de sol a sol como empregada doméstica, e ela era muito requisitada porque ela foi criada em Lomba Grande em casa de alemães, então ela tinha o capricho, era muito caprichosa. Então os dois se tornaram um casal de trabalhadores para sustentar os filhos, que aí veio... Começaram a vir mais filhos, nós somos seis irmãos. E ele naquela envernizaria brigando com o patrão e minha mãe fazendo faxina p'ra buscar o sustento para a família."

Neste caso, faz-se necessário compreender as representações acerca deste "mundo alemão" não apenas na relação com os negros, mas no contexto da sociedade rio-grandense como um todo, isto é, no plano da reconstrução das imagens da campanha e da figura do gaúcho e dos seus gestos de ocupação territorial e de formação das cidades ao longo dos tempos.

\section{AS IMAGENS POLÊMICAS DOS NEGROS NO MUNDO ALEMÃO DO VALE DO RIO DOS SINOS}

A forma sociológica do "estrangeiro" em Simmel (1983) é, neste ponto, relevante de ser retomada para interpretar a complexidade das relações espaciais que reuniam alemães (o trabalho livre de origem europeia) e negros (o trabalho livre de ex-escravos) em seu território de destino - a região do Vale do Rio dos Sinos, ao longo do século XX. Para o autor, a figura do estrangeiro não é só a daquele que vem de fora, mas a daquele que torna nítida a diferença. 
Quando Simmel (1983) analisa o fenômeno do estrangeiro, discorre sobre as formas de interações sociais orientadas por uma tensão particular entre a proximidade e a distância. Aplicando-se a metáfora do estrangeiro - a pessoa que chega hoje e amanhã fica - para a interpretação do mundo do trabalho no Vale do Rio dos Sinos, podemos entender, por um lado, os laços simbólicos que unem a figura do imigrante alemão e da região do Vale do Rio dos Sinos à figura do gaúcho e da paisagem da campanha como parte do mito de fundação da sociedade rio-grandense. Por outro lado, podemos compreender os laços simbólicos que reúnem a figura do negro e do trabalho escravo à figura do colono alemão e do trabalho livre como parte do mito de fundação da civilização urbana e industrial no Vale do Rio dos Sinos. As figuras do negro e do imigrante alemão de diferentes formas, contrapostas à figura lendária do gaúcho em relação à região do pampa no Rio Grande do Sul, apontam para esta condição de estrangeiro, uma vez que esses não são proprietários de terra - "não apenas no sentido físico de terra, mas também no sentido figurado de uma substância vital que é fixa" (Simmel 1983: 187).

Assim, em adesão ao formismo simmeliano, ${ }^{14}$ consideramos que, embora existam algumas marcas simbólicas que aproximem negros e alemães à figura do gaúcho em termos de heroicidade no mundo do trabalho, nem um nem outro representam as origens da sociedade rio-grandense, uma vez que, atuando na condição de "estrangeiros", são situados de forma distanciada a ela, no plano do imaginário.

$\mathrm{Na}$ interpretação do colono como representando "o estrangeiro" no Rio Grande do Sul, acrescentamos que, neste caso, a figura do alemão sintetizou o ideal do europeu branco, protótipo da cultura anglo-saxônica e de sua ética do trabalho em pleno berço da civilização católica nos trópicos. ${ }^{15}$ Ao contrário do português e do espanhol, cujas imagens de europeus foram denegadas em virtude da miscigenação com negros e índios, o alemão representou a preservação da "branquidade".

Novamente, nas palavras de um de nossos interlocutores, o Sr. Alcides, com 74 anos na ocasião da pesquisa, aparece a ênfase de que "os negros só trabalhavam no curtume, só curtimento, não trabalhavam em fábrica de calçado":

"E, naquela época, eu não tenho certeza, mas meu pai contava que negro não trabalhava em calçado, só em curtume, só curtimento, porque tinha

14 A expressão "formismo" é aqui empregada no sentido utilizado por M. Maffesoli (2009), quando o autor postula a pertinência do paradigma estético para a compreensão da singularidade da produção intelectual de Georg Simmel, um pensamento que se propõe refletir sobre a vida social aderindo ao vitalismo de suas formas. $\mathrm{O}$ autor se opõe, assim, ao postulado positivista que insiste em enfocar a obra de G. Simmel a partir de um enfoque "formalista", numa visão tecno-utilitarista do conhecimento.

15 O uso da expressão "ética do trabalho" tem referência na obra clássica de Max Weber (1996), A Ética Protestante e o Espírito do Capitalismo. 
muitos curtumes, aqui, em Novo Hamburgo. [...] Eu não senti isso, mas o meu pai contava que os negros só trabalhavam no curtume, só curtimento, não trabalhavam em fábrica de calçado. O meu pai sempre trabalhou em curtume, se aposentou pelo curtume."

O tema das relações inter-raciais plurais aparece repetidas vezes mesclado a essa experiência urbana conflitiva em referência ao lugar que os negros ocupavam no mundo do trabalho da "Manchester brasileira", conforme aparece na fala do Sr. Lair, outro de nossos interlocutores de pesquisa, quando relata sua experiência geracional na vida urbana de Novo Hamburgo:

“A raça negra na década de 70, em Novo Hamburgo, p’ra conseguir um emprego, ou era como servente de pedreiro, ou era num curtume. Nas fábricas de calçado tinha aquela dificuldade para a pessoa se empregar. Eles olhavam... Às vezes estavam com cem vagas ali, olhavam p'ra tua cara e diziam: não tem vaga. O preconceito era grande. [...] Os negros trabalhavam mais em curtume ou eram servente[s] de pedreiro. Parte era por conhecimento profissional e era [a]o que eles mais se adaptavam. A raça negra se adaptava mais nesse tipo de setor. Portanto, era muito reduzido na fábrica de calçado."

As marcas do valor trabalho e de sua ética amplamente relacionada ao mundo do trabalho livre e associadas à imagem, na região, dos imigrantes alemães reverberam na voz dos nossos narradores negros como um elemento balizador das suas trajetórias sociais e das de seus descendentes, em Novo Hamburgo. O fenômeno pode ser observado nos jogos da memória do Sr. Fladimir, 70 anos, outro de nossos parceiros de pesquisa:

“As empresas eram... P'ra quem gostava de trabalhar, era bom, né? [risos] Eles davam muitos empregos assim, mas se vacilasse, saía... O mercado era muito grande de serviço. Aí logo pegavam a gente. Podia mudar [de emprego], mas não convém, a pessoa não deve trocar muito de serviço. Porque é carteira assinada e isso aí na carteira vale muita coisa, a pessoa pular de firma em firma... Eles vão pegar a pessoa, já a primeira coisa que eles falam: 'Pô, mas aqui trabalhou um mês nessa firma, por quê?' [...] Nunca gostei de faltar serviço. Eu sempre fui daquele pensamento: se vou sempre ter que levantar [às] cinco horas para ir trabalhar, vou p'ra dentro da firma p'ra esculhambar? P'ra quê? Então eu sempre... Eu ficava até anos em firma. Ah, eu gostava, eu gostava do serviço."

Entretanto, é importante registrar que a ética do trabalho tal qual apresentada por Sr. Fladimir, e agenciada por gerações de descendentes dos ex-escravos, 
em suas interações cotidianas no mundo da produção industrial coureiro-calçadista com os descendentes dos primeiros colonos alemães do Vale do Rio dos Sinos, trava, no tempo presente, um diálogo silencioso com a ética da malandragem e a figura do malandro que ainda perdura, nos dias de hoje, no imaginário da sociedade brasileira. Esta ética funda uma estética, fruto das teorias raciais da formação do caráter dos "brasileiros", que buscavam explicar o fracasso da "civilização" no Brasil em razão da miscigenação dos portugueses conquistadores com índios e negros sob os trópicos. Acordar cedo, gostar de trabalhar, não "esculhambar" são valores que se sintonizam com as imagens arcaicas de Novo Hamburgo como cidade ordeira, laboriosa, projetada para o "progresso" e o "desenvolvimento". ${ }^{16}$

É interessante assinalar que a pesquisa à qual nos referimos transcorreu precisamente num período em que o Vale do Rio dos Sinos encontra-se submerso na crise dos valores propagados pelo mito do progresso na região de Novo Hamburgo. Neste momento singular, a indústria coureiro-calçadista colapsa com o deslocamento de algumas empresas para outras regióes do país e, logo após, para o exterior, assim como o fechamento de outras tantas indústrias, deixando apenas as lembranças da antiga agitação e vibração do mundo do trabalho para seus herdeiros urbanos. Contrapostas aos espaços vazios das antigas ruas e pavilhões da vida industrial em Novo Hamburgo, nas sociabilidades dos mais antigos em clubes e associações despontam as lembranças vividas no interior das fábricas, dos objetos de trabalho, dos espaços partilhados com outros operários negros, das ruas abarrotadas de homens e mulheres deslocando-se em direção aos locais de trabalho, de um tempo partilhado socialmente, os quais oferecem a sensação de permanência e estabilidade às coisas desse mundo.

Ao narrar sobre a experiência dos mineiros de carvão da cidade de La Grand-Combe, no Sudeste da França, Eckert (1993) assinala que o tempo presente enunciado por eles, o do fechamento das minas, guarda uma ligação intrínseca com o passado, pois as evocações do vivido engendram uma continuidade, um devir nas sociabilidades das feiras e das festas coletivas em torno das quais se reúnem os seus herdeiros urbanos. Atingida pela recessão econômica, a comunidade de trabalho de La Grand-Combe reordena seu tempo coletivo, onde aparecem como superpostos o "tempo da mina" e o "tempo da crise", cujos arranjos revelam o esforço dessa comunidade para pensar um encadeamento entre o tempo passado e o tempo presente, superando as rupturas e descontinuidades do tempo vivido (Eckert 1993).

16 Estas imagens e representações eram muito presentes na mídia impressa, especialmente no Jornal NH, em meados da década de 1970, período em que a industrialização avançou a passos largos devido à exportação (Nunes 2009). 
Como aponta a experiência dos mineiros de carvão, na França, relativamente ao fim de sua vida de profissão com o fechamento das minas, observamos que as narrativas dos trabalhadores negros apresentam esta feição de arranjo das estruturas espaçotemporais superpostas, do tempo da abundância e fartura e do tempo da crise, que marcam a rítmica do mundo dos brancos no Vale do Rio dos Sinos:

"Novo Hamburgo, por exemplo, tinha ruas que você caminhava, travessas e ruas dos dois lados, esquerda e direita, monumentais prédios, pavilhões, fábricas, casas velhas modificadas, remodeladas para fazer fabriqueta, todos os porões eram fabriquetas. Na hora das 7 horas, tinha que ver o movimento da hora do pico, o meio-dia, um movimento descomunal, à noite também, fábrica apitando, olha, era um hino de fábrica apitando. Trabalhando até 10 horas da noite, virando noite, sábado era o dia inteiro, quando não ia trabalhar um pouco domingo, até meio-dia, para dar conta dos pedidos que o patrão tivesse, para embarcar a produção para Porto Alegre ou Rio Grande, tomar o rumo para a Europa. Hoje o que estou falando não existe mais mesmo" [Sr. Francisco].

Diferente do mundo da circulação do capital, o mundo da esfera do trabalho onde os negros se situam revela, por um lado, a marca do "tempo das fábricas”, que é o tempo do emprego abundante, da grande circulação de operários, dos prédios monumentais, das fábricas e das fabriquetas espalhadas pelas ruas e ruelas, o tempo do barulho das "fábricas apitando", e revela, por outro, a marca do "tempo da crise", que é o tempo da escassez dos postos de trabalho, do abandono dos prédios, das ruínas, do silêncio, pois quase não se ouve mais esse "hino de fábricas apitando".

Se nas narrativas etnobiográficas dos negros há pontos de encontro com o ethos e a visão de mundo atribuída ao "mundo dos brancos", os elementos que se entrelaçam ocorrem em razão dos sentimentos de um tempo partilhado socialmente em face de sua condição similar no mundo da produção local. Entretanto, nos jogos da memória dos trabalhadores das indústrias coureiro-calçadistas da região do Vale do Rio dos Sinos, muitas são as experiências singulares vividas pelas populações negras, marcadas por formas de distinção simbólica, as quais estão associadas às diferenciações de raça e etnia no interior dos bairros proletários da cidade. ${ }^{17}$ Segundo os relatos de nossos interlocutores,

17 Segundo Bourdieu (1983), existem diferenças objetivas entre os sujeitos e os grupos devido à posição ocupada na estrutura social, e essas diferenças transmutam-se em "distinções simbólicas", definindo gostos, preferências e estilos de vida. Ao utilizarmos o conceito neste trabalho enfatizamos as dimensões simbólicas das quais se revestem as diferenças etnicorraciais. 
nos espaços urbanos havia a divisão entre o "mundo dos negros" e o "mundo alemão" e, ainda, o "mundo dos brasileiros" - chamados de "pelos duros" -, do qual os negros tampouco participavam.

Assim, as narrativas dos trabalhadores negros trazem à tona as desigualdades etnicorraciais existentes, não apenas na edificação das origens do mundo do trabalho industrial, mas nas experiências vividas por esses trabalhadores nos espaços de sociabilidade pública da cidade, onde vigorava uma lógica social e racial excludente:

"Quando eu era criança, o bairro África [hoje denominado de Guarani] era, era época de guerra, né? Segunda Guerra Mundial. Então o meu pai trabalhava, trabalhava no curtume e a minha mãe era doméstica, e a gente tinha nos finais de semana uns clubes de futebol. E isso aqui era... Essa área aqui, o bairro era dividido. A rua Demétrio Ribeiro, isso até hoje quase é assim, não é tanto... Mas era dividido. Aquela parte de cima, quem sobe à esquerda, eram só os de origem alemã que moravam ali. E no lado de baixo, da direita, ali, é que moravam os brasileiros e os 'pelos duros', que a gente chama. E negro também morava ali. Era dividido assim, não sei o porquê assim, mas os alemães moravam todos do lado de lá e os negros do outro lado" [Sr. Alcides, 74 anos].

Florestan Fernandes (2007) mostra com esmero o quanto o conceito de brasilidade foi elaborado pelos intelectuais à revelia das experiências vividas pelas populações negras e outras minorias étnicas ou raciais no país. Para construir este raciocínio, o autor tenta demonstrar o quanto o "dilema racial brasileiro" é estrutural, pois, mesmo após a abolição da escravatura, no período da instauração da República, a velha ordem racial manteve-se intacta. Para o sociólogo, a abolição apenas alterou o estatuto jurídico do negro, sem que ele pudesse, de fato e de direito, na condição de liberto, experimentar uma situação de classe, razão pela qual, para o autor, a nova ordem social que instituía o trabalho livre não rompeu com a sociedade de castas que orientava as relações inter-raciais no Brasil. Assim, o "mundo tradicionalista brasileiro" sobreviveu e continuou atualizando-se por meio da estreita relação entre cor e posição social. O autor afirma que o "abrasileiramento" foi um processo de branqueamento das populações negras, uma vez que tal processo construiu uma identidade brasileira para os ex-escravos, a partir da sua condição de exclusão no interior da sociedade de classes, ainda em processo de gestação no Brasil.

Uma afirmação contundente sobre as relações entre cor e posição social no Brasil pós-abolição reverbera de forma vigorosa na voz de uma das nossas narradoras, Manuela, quando nos conta sobre o mundo do trabalho que separava alemães, pelos duros e negros no Vale do Rio dos Sinos: 
"No trabalho tinha uma senhora, lá, que era meio racista, mas eu não dava bola. Um dia a gente estava trabalhando, escovando as paredes do corredor e ela brava, e ela não viu eu chegando. Daí ela disse: 'esse serviço aqui era p'ra negro fazer, não p'ra gente.' Aí eu disse para ela: 'O que tu falaste?' Ela quis disfarçar. 'Mas eu ouvi o que tu falaste, tu és racista, eu sabia.' Aí, nisso, a chefa chega, ela perguntou o que era. Daí eu disse: 'A Melita está com racismo dizendo que isso aqui é p'ra negro.' A chefa a chamou lá no canto e chamou a atenção dela. Disse que não admitia isso e disse que todos eram iguais, que todos tinham que trabalhar unidos e que não queria mais saber disso. A chefa era muito carrasca, mas não era racista."

As relações de poder unindo "negros" e "brancos", alemães e "brasileiros" ao mundo da produção de Novo Hamburgo destacam-se em outras narrativas que explicitam a continuidade dos valores da "velha ordem social" escravocrata e racista no interior do mundo do trabalho livre, como ponderava Florestan Fernandes em seus estudos. Tal perspectiva é observada nas interlocuções estabelecidas por Magalhães (2010) com descendentes de ex-escravos no Vale do Rio dos Sinos por decorrência da discussão acerca da importância do associativismo negro em Novo Hamburgo. A memória coletiva dos descendentes negros traz à tona o preconceito racial e as lembranças da demarcação de espaços de circulação do negro na cidade.

Uma separação rígida do mundo dos brancos e dos negros não ocorria apenas às portas fechadas dos estabelecimentos e instituições, mas se ampliava para as formas de ocupação dos espaços públicos de Novo Hamburgo. Dona Nair, mulher negra que trabalhou muito tempo como empregada doméstica para uma importante família de Novo Hamburgo, ao lembrar as tardes de domingo e o encontro com amigas na praça central da cidade, relata que ela e suas amigas "sentavam no banco da praça [...] podia sobrar lugar [...] passava a tarde toda [...] ninguém sentava do nosso lado". Dorneles, trabalhador negro que nos anos 40 do século XX tornou-se morador de Novo Hamburgo no intuito de ter mais oportunidades de trabalho e melhores condições de vida, enfatiza o código de emoções com o qual reagiam as populações negras às severas restrições impostas a elas pelos "brancos" no que se referia a sua circulação pela cidade. Por outro lado, assinala as táticas e astúcias (De Certeau 1994) empregadas pelos negros para exercitar seu direito à cidade: “[...] nós evitávamos entrar em lugares que não queriam a nossa presença, se tinha uma loja que não queria a nossa presença, evitávamos ir ali”.

\section{CONSIDERAÇÕES FINAIS}

Ao longo do registro etnográfico das memórias dos negros no interior do mundo do trabalho de Novo Hamburgo, em especial, destaca-se o teor 
discriminatório com que os herdeiros urbanos das populações de ex-escravos foram sendo absorvidos pelo regime de trabalho livre e seu universo de direitos civis, com fortes fragmentos de lembranças de uma memória étnica injuriada pelo "mundo dos brancos".

As narrativas apontam, também, para experiências urbanas marcadas por uma lógica social e racial onde os diferentes grupos- "alemães", "brasileiros" e "negros" são acomodados em espaços distintos da cidade, compondo assim "mundos" que atualizam mecanismos tradicionais de distinção social associada à cor.

As péssimas condições de vida e de moradia e a inserção como trabalhador assalariado no lado mais sombrio da indústria coureiro-calçadista da região revelam uma população cujo direito à cidade foi subtraído, resultando disso todo um universo de práticas sociais de resistência cujos territórios hoje têm uma importante carga simbólica para os movimentos sociais dos afrodescendentes em Novo Hamburgo, como os times de futebol, as associações carnavalescas e os clubes de negros.

As populações negras do Vale do Rio dos Sinos buscam na esfera do trabalho elementos para atribuir às suas memórias uma dignidade e valor no interior do mundo dos "alemães". Através do culto à ética do trabalho, ainda que exercido no interior de condições de alta periculosidade e insalubridade, homens e mulheres negros, herdeiros urbanos dos ex-escravos da região, procuram dignificar suas trajetórias sociais e situar sua participação nos mitos de fundação da cidade de Novo Hamburgo. É no mundo do trabalho que essas populações se ancoram para sustentar seu protagonismo na vida social e política da região, no esforço de tecer os fios que as unem a uma "comunidade de trabalho" atingida pelas crises do capital num mundo globalizado. Desse modo, qualificam a sua experiência coletiva como trabalhadores negros.

A valoração positiva do trabalho nos curtumes e o protagonismo negro na produção coureiro-calçadista no Vale do Rio dos Sinos é uma história a ser contada por seus próprios habitantes e trabalhadores negros, para a busca da visibilidade e do reconhecimento desse grupo etnicorracial na edificação do trabalho e do desenvolvimento da região. 


\section{BIBLIOGRAFIA}

ALVES, Eliege Moura, 2005, "Uma presença invisível: escravos em terras alemãs (1850-1870)", em Margarete Fagundes Nunes (org.), Diversidade e Políticas Afirmativas: Diálogos e Intercursos. Novo Hamburgo, Feevale, 154-168.

ANDREWS, George R., 1998, Negros e Brancos em São Paulo (1888-1988). São Paulo, Edusc. BOURDIEU, Pierre, 1983, "Gostos de classe e estilos de vida", em Renato Ortiz (org.), Pierre Bourdieu: Sociologia. São Paulo, Ática, 82-121.

CARDOSO, Fernando Henrique, 1977, Capitalismo e Escravidão no Brasil Meridional: O Negro na Sociedade Escravocrata do Rio Grande do Sul. Rio de Janeiro, Paz e Terra.

CESAR, Guilhermino,1970, História do Rio Grande do Sul: Período Colonial. Porto Alegre, Globo.

DE CERTEAU, Michel, 1994, A Invenção do Cotidiano, vol. 1. Petrópolis, Vozes.

DURAND, Gilbert, 2002, As Estruturas Antropológicas do Imaginário. São Paulo, Martins Fontes.

ECKERT, Cornelia, 1993, "Ritmos e ressonâncias da duração de uma comunidade de trabalho: mineiros do carvão (La Grand-Combe, França)", Cadernos de Antropologia, 11 : $1-84$.

ECKERT, Cornelia, e Ana Luiza Carvalho da ROCHA, 2005, O Tempo e a Cidade. Porto Alegre, Editora da UFRGS.

ECKERT, Cornelia, e Ana Luiza Carvalho da ROCHA, 2009, "Memória e ritmos temporais: o pluralismo coerente da duração no interior das dinâmicas da cultura urbano-contemporânea”, Estudos Históricos, 22 (43): 105-124.

FERNANDES, Florestan, 2007, O Negro no Mundo dos Brancos. São Paulo, Global.

FERNANDES, Florestan, 2008, A Integração do Negro na Sociedade de Classes: No Limiar de Uma Nova Era, vol. 2. São Paulo, Globo.

GUimarães, Josué, 1996, A Ferro e Fogo I: Tempo de Solidão. Porto Alegre, L\&PM.

KUHN JÚNIOR, Norberto; e Margarete Fagundes NUNES, 2012, "The role of the new media in the migratory experiences of Brazilian footwear industry workers in the south of China, Migraciones Internacionales, 6 (4): 47-74, disponível em: <http://www2. colef.mx/migracionesinternacionales/revistas/MI23/02-MI23-47-74.pdf $>$ (acesso em 30/4/2013).

MAFFESOLI, Michel, 2009, "Vers un 'formisme' sociologique”, Sociétés, 105: 79-90.

MAGAlHãeS, Magna Lima, 2010, Entre a Preteza e a Brancura Brilha o Cruzeiro do Sul: Associativismo e Identidade Negra em Uma Localidade Teuto-Brasileira. São Leopoldo, Unisinos, Programa de Pós-Graduação em História, tese.

MORAES, Carlos de Souza, 1980, "Sesmarias: legislação e seus reflexos na colonização alemã”, em Telmo Lauro Müller (org.), Imigração e Colonização Alemã. Porto Alegre, EST, 165-229.

MOrAeS, Carlos de Souza, 1994, Feitoria do Linho Cânhamo. Porto Alegre, Parlenda.

NUNES, Margarete Fagundes, 2009, "O Negro no Mundo Alemão": Cidade, Memória e Ações Afirmativas no Tempo da Globalização. Florianópolis, Universidade Federal de Santa Catarina, Programa de Pós-Graduação em Antropologia Social, tese.

OLIVEN, Ruben George, 1996, "A invisibilidade social e simbólica do negro no Rio Grande do Sul", em Ilka Boaventura Leite (org.), Negros no Sul do Brasil: Invisibilidade e Territorialidade. Florianópolis, Letras Contemporâneas, 13-32. 
PEREIRA, José Maria Dias, 2002, "Um modelo teórico para explicar a transferência de capital entre regiões desigualmente desenvolvidas aplicado ao caso da indústria de calçados", Ensaios FEE, 23 (2): 923-948, disponível em < http://revistas.fee.tche.br/index. php/ensaios/article/viewArticle/2047> (acesso em 30/4/2013).

PETRY, Leopoldo, 1944, O Município de Novo Hamburgo. Porto Alegre, Edições A Nação.

PORTO, Aurélio, 1934, O Trabalho Alemão no Rio Grande do Sul. Porto Alegre, Editora e Gráfica Terezinha.

PRELORAN, Jorge, 1987, El Cine Etnobiográfico. Madrid, Busqueda de Ayllu.

SIMMEL, Georg, 1983, "O Estrangeiro", em Evaristo Moraes Filho (org.), Georg Simmel: Sociologia. São Paulo, Ática, 182-188.

TITTONI, Jaqueline, 2007, Trabalho, Poder e Sujeição: Trajetórias entre o Emprego, o Desemprego e os "Novos" Modos de Trabalhar. Porto Alegre, Dom Quixote.

VELHO, Gilberto, 1999, Projeto e Metamorfose: Antropologia das Sociedades Complexas. Rio de Janeiro, Zahar.

Weber, Max, 1996, A Ética Protestante e o Espírito do Capitalismo. São Paulo, Editora Pioneira. WEIMER, Gunter (org.), 1987, A Arquitetura no Rio Grande do Sul. Porto Alegre, Mercado Aberto. 